\title{
Simple approach to elaborate test bricks for traditional ceramic studies
}

\author{
Hicham Idrissi ${ }^{\left(1^{*}\right)}$, Wafaa Borja ${ }^{(1)}$, Nathalie Fagel ${ }^{(2)}$, Lahcen Daoudi ${ }^{(3)}$
}

(1) Materials Science, Energy and Nanoengineering Department (MSN), Mohammed VI Polytechnic University (UM6P), Lot 660.Hay Moulay Rachid, 43150, Ben Guerir, Morocco.

(2) UR, AGEs, Département de Géologie, Université de Liège, Quartier Agora, Bâtiment B18, Liège 4000, Belgium.

(3) Laboratoire de Géoressources, Géoenvironnement et Génie civil (L3G), Faculté des Sciences et Techniques, Université Cadi Ayyad, B.P.549, Marrakech.

\begin{abstract}
Fired bricks have shown tremendous potential as a construction material due to their properties. However, their use required some specifications in terms of quality, resistance, and durability. In developing countries, the lack of tools to make test specimens leads to many defects in these brick specimens responsible for low durability and weak precision during mechanical tests and shrinkage. In this study, a simple and traditional method of making test bricks is presented. This simple method allows the production of bricks with the required properties. This method is especially efficient for a firm or semi-soft pastes consistency. The handmade pastes do not stick into the walls of the mold like the case of steel molds and it gives specimens with standard shape, smooth surface, and sharp edges. The resulting fired bricks exhibit high mechanical strength comparable and even better than those of conventional methods.
\end{abstract}


24 Keywords: Test bricks; Fired bricks; handmade bricks; ceramics; mechanical 25 strengths.

26

27

28

\section{Introduction}

Since the $19^{\text {th }}$ century, efficiency and durability are important criteria in the design concerns of materials construction. For that reason, making tests on these construction materials before using them is a necessity. Fired bricks are considered one of the main construction materials because of their low cost and durability. However, the type of equipment used to elaborate test specimens influences their quality and the results obtained for the drying and the mechanical strength studies.

Different appropriate routes of molding were taken to prepare bricks such as Table molding and Ground-Molding. They give bricks that contain standard shapes, sharp edges, and smooth surfaces. Most test specimens were made by cylindrical or rectangular molds and then pressed by a hydraulic press under specific pressure. However, this method is only adapted for dry samples but not for wet pastes unlike the extrusion process but that requires unaffordable tools for small laboratories. Additionally, not every researcher that is undertaking a new study on clayey materials for fired bricks making have the necessary tools for test bricks making. As a result, researchers are forced to rely on their own way of making bricks or to delay their study. Moreover, several research works were carried out in developing countries on building materials based on clays [1]-[3] and an alternative affordable way is a necessity for them. 
With the limited access to the tools of making bricks specimens for mechanical

46

47

48

49

50

51

52

53

54

55

56

57

58

59

60

61

62

63

64

65

tests, our work is intended to provide and describe an easy and practical laboratory

scale method of molding, for ceramists working in developing countries. This method was applied in previous papers without giving the details of how to elaborate the test

bricks [4], [5] and it generated very promising results comparing with the tools that are available in industrialized nations [6], [7].

\section{Manufacturing procedure}

The adopted method was developed at the Georesources, Geoenvironment and Civil Engineering Laboratory (L3G) of the Faculty of Sciences and Techniques of Marrakech. It is an artisanal elaboration of test bricks according to the device presented in Figure 1. The produced specimen presents the following dimensions: 1 $\mathrm{cm}$ in thickness, $3 \mathrm{~cm}$ in width and $15 \mathrm{~cm}$ in length as shown in Figure 1.

To elaborate homogenous test bricks in terms of thickness, two small wooden plates of $1 \mathrm{~cm}$ of thickness were used as a wedge during the pressing of the pastes. Then, the other wooden plate is superimposed on a paper of the same basal dimension. Two small wooden plates $1 \mathrm{~cm}$ thick serve as a wedge during pressing to obtain bricks of the same thickness.

After pressing, the wooden plate is superimposed on a paper of the same basal dimension. The basal surface of the wooden plate corresponds to that of the brick to be developed. The brick is then cut with a sharp blade using this wooden plate as a template. 

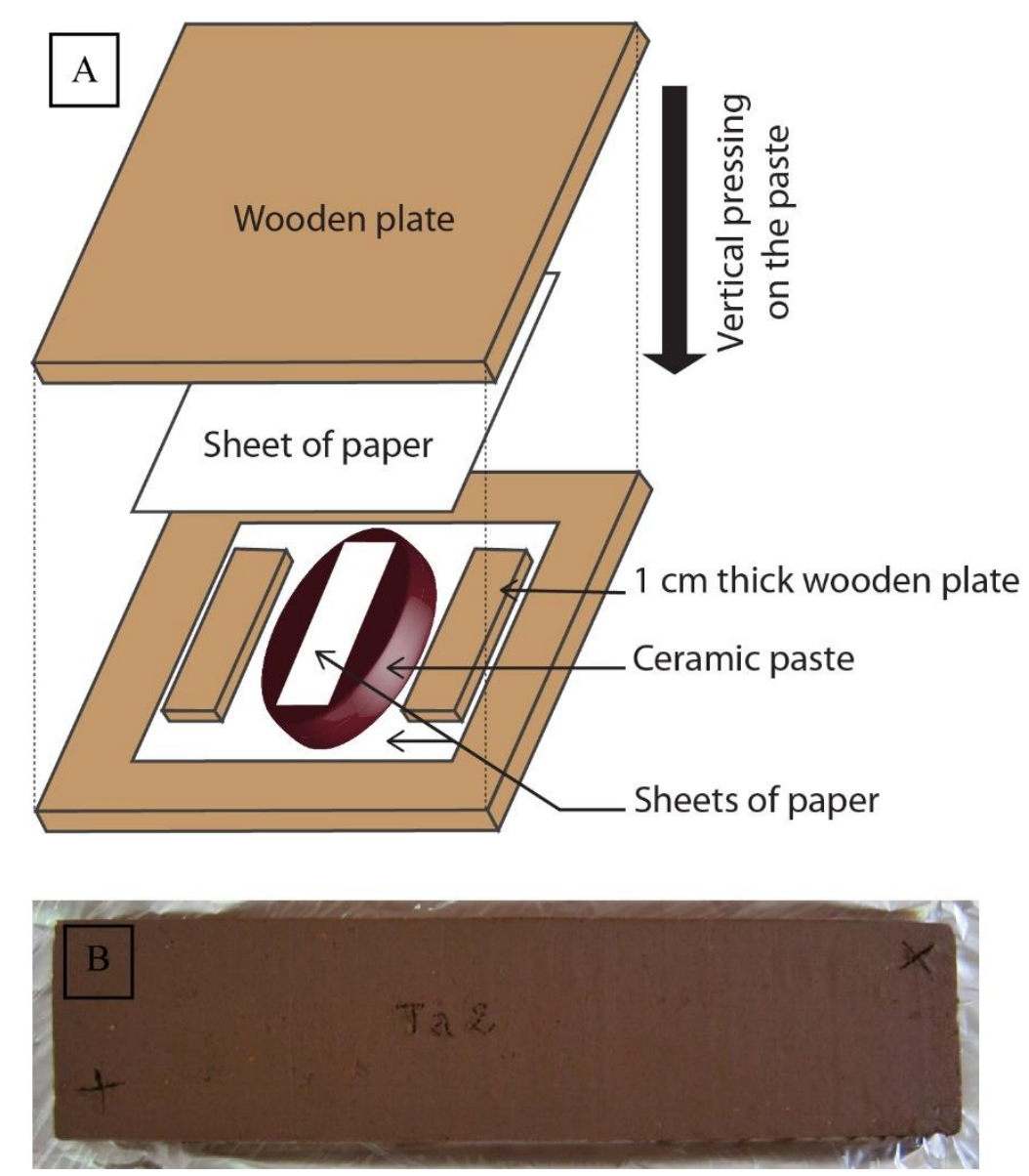

Figure 1: (A) Device for producing test specimens by the proposed method. (B) Example of a test specimen with the two reference crosses for measuring shrinkage.

The upper paper attached to the prepared wet brick is removed and replaced with aluminum foil (previously weighed) which will serve as a tray for the brick. The assembly is turned over to remove the plate and the bottom paper. Marks are made with a point on the two diagonal ends of the brick. They will allow to measure the change in the length between these two points as a function of time. Then the length of the brick and its weight are measured to get information about the drying shrinkage and the loss on weight during drying respectively.

The mechanical resistance to compression is achieved on cylindrical specimens. They are made by rolling up a semi-soft paste (which does not stick to the fingers) to 
78 form a clay coil $10 \mathrm{~cm}$ in length and $2 \mathrm{~cm}$ in diameter. Then we keep $4 \mathrm{~cm}$ from the 79 middle of the coil, and we cut the edges carefully with a well cleaned sharp blade. 80 Finally, we let it dry gently in the shade to prevent rapid drying that could cause 81 cracking.

After firing three rectangular and three cylindrical test specimens for each sample at the desired temperature, we can carry out the mechanical flexion strength test for

84 the former and to the compressive strength test for the latter. The Erreur! Source du renvoi introuvable. shows an example of the elaborated test bricks at different perspectives: wet, dry and fired. large volume of air gets trapped in the base of the specimen resulting in an improper shape. Also, during demolding, the walls of the mold stick to the paste and their detachment deforms the test specimen. Even if the shape is manually restored, the overall grain arrangement changes what is reflected and becomes visible as the drying process progresses and the brick becomes twisted from its original shape. This problem does not exist in the proposed method since the papers used during pressing

94 make it possible to prevent the wooden planks from sticking to the ceramic paste. 

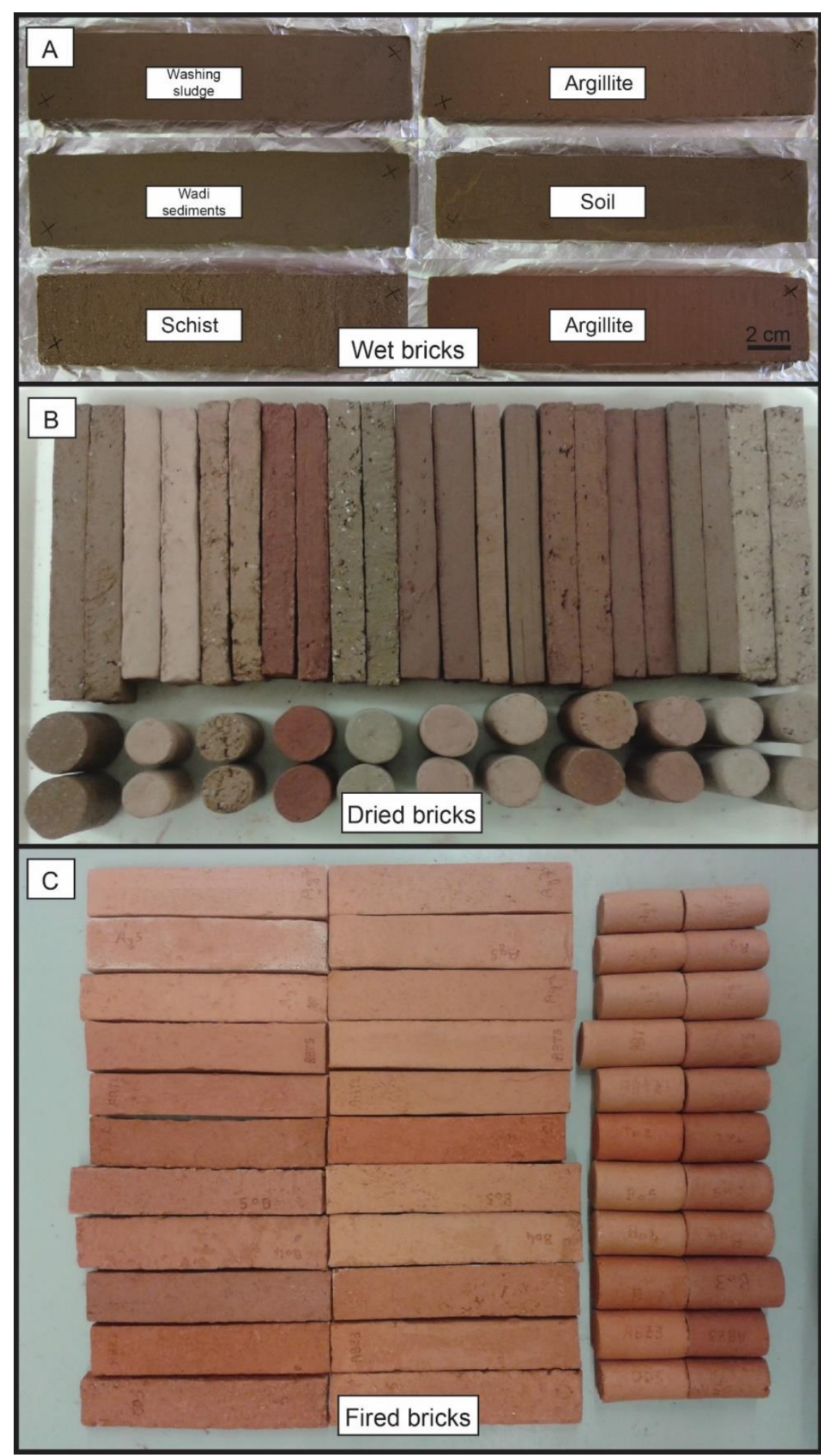
99

100

101

102

103

104

105

106

107

108

109

110

111

112

113

114

115

116

117

\section{Data measurement}

On laboratory scale, the manufacturing of the brick specimens requests several measurements.

(1) The length measurements are taken from the two diagonal marks to calculate the drying shrinkage according to the equation 1:

$$
\% \mathrm{Ds}=\frac{(L i-L f)}{L i} \times 100 \text { eq. } 1
$$

where Ds is the drying shrinkage, $\mathrm{Li}$ is the length between the two marks before drying and $L f$ is the length between the two marks after the end of drying.

(2) At the same time, the measurement of the loss in weight on drying can be measured according to the equation 2:

$$
\% \mathbf{W L}=\frac{(M i-M f)}{M i} \times 100 \quad \text { eq. } 2
$$

where $\mathrm{WL}$ is the weight loss after the end of drying, $\mathrm{Mi}$ is the initial mass of the moisturized specimen and $\mathrm{Mf}$ is the final mass at the end of drying.

After firing at the desired temperature, the firing shrinkage can be measured according to the equation 3 :

$$
\% \mathrm{Fs}=\frac{(L d-L f)}{L d} \times 100 \text { eq. } 3
$$

where Fs is the firing shrinkage at a given temperature, Ld is the length between the two marks after drying and $L f$ is the length between the two marks after firing.

Simultaneously, the measurement of the firing weight loss can be measured

118 according to the equation 4: 


$$
\% \mathbf{W L f}=\frac{(M i-M f)}{M i} \times 100 \quad \text { eq. } 4
$$

where WLf is the weight loss after the end of the firing process, Mi is the initial mass of the dried specimen and $\mathrm{Mf}$ is the final mass at the end of the firing. The establishment of the Bigot curve that allows to characterize the shrinkage

123 efficiently will be detailed in a future programed paper based on this technic of bricks 124 elaboration.

125 The mechanical flexural and compressive strengths are deduced from the 126 maximum stress before rupture according to the equation 5 and 6 respectively:

$$
\boldsymbol{F} \boldsymbol{f}=\frac{\boldsymbol{f} \times \boldsymbol{l}}{\boldsymbol{d}_{1} \times \boldsymbol{d}_{2}^{2}} \quad \text { Eq. } 5
$$

128 where $F f$ is the flexural strength expressed in $\mathrm{MPa}, f$ is the maximum load in newtons, $l$ is the distance between the support cylinders, $d_{1}$ and $d_{2}$ are the lateral dimensions of the specimen in $\mathrm{mm}$ (width and thickness respectively).

$$
\boldsymbol{F} \boldsymbol{c}=\frac{\boldsymbol{f}}{\boldsymbol{A}} \quad \text { Eq. } 6
$$

where $F c$ is the compressive strength expressed in MPa, $f$ is the maximal load expressed in newtons and $A$ is the surface section of the specimen to which the compressive force is applied, expressed in $\mathrm{mm}^{2}$.

On average, the test pieces have a dimension of $2 \times 4 \mathrm{~cm}$ for cylindrical shaped test specimens and a dimension of $10 \times 2 \times 1 \mathrm{~cm}$ for rectangular shaped test specimens. 
139

141

142

143

144

145

146

148

149

150

151

152

153

154

155

156

157

158

159

160

\section{Example of the application of the method on clayey raw materials}

The efficiency of the method was tested on various materials, i.e., schist (5 samples), colluviums (5 samples), soils (3 samples), washing sludges (2 samples), argillites (6 samples), and river sediments ( 3 samples). After crushing and grinding of these raw materials, water was added until obtaining a good consistency of the pastes. This method is most efficient with semi-soft to firm paste. The elaborated bricks are uniform, and they conserve their form after a complete drying if the process is applied delicately.

The data measured from the elaborated bricks are represented in Table 1 . The drying shrinkage rates range between 3 and 10\%, while the drying weight loss sweep between 15.3 to $36.6 \%$. The firing shrinkage presents lower values varying between 0.3 and $4.9 \%$, whilst the firing shrinkage orbits between 4.8 to $13.2 \%$.

The firing temperature for the specimens was $1050{ }^{\circ} \mathrm{C}$ according to the recommendation of many authors [8]-[11] to produce a good quality ceramic. The firing process was done at a rate of $3{ }^{\circ} \mathrm{C} / \mathrm{min}$ and holding for 30 minutes at the maximum temperature. The measurements were done by a "Testometric Micro350" for the flexural strength according to the European Standard [12] and a compression machine made at ArGEnCo Laboratory (University of liege) for the compressive strength according to the European Standard [13], equipped with a worm gear motor NEFF and controlled by a Microstep Drive (Parker) and a compumotor PC23 adaptator. 
Table 1: Data measured from the elaborated bricks.

162 \%Ds: Drying shrinkage ; \%WL: Drying weight loss; \%Fs: Firing shrinkage; \%WLf: Firing weight loss; Ff: Flexural strength; Fc: Compressive strength.

\begin{tabular}{|c|c|c|c|c|c|c|c|}
\hline Lithology & Samples & $\% \mathrm{Ds}$ & $\% \mathrm{WL}$ & $\% \mathrm{Fs}$ & $\% \mathrm{WLf}$ & $\mathrm{Ff}(\mathrm{MPa})$ & $\mathrm{Fc}(\mathrm{MPa})$ \\
\hline \multirow[t]{7}{*}{ Schist } & S1 & 4.6 & 16.6 & 0.3 & 4.8 & 42 & 9 \\
\hline & S2 & 4 & 15.3 & 0.8 & 4.8 & 43 & 10 \\
\hline & S3 & 4.2 & 18.5 & 0.7 & 9.1 & 28 & 10 \\
\hline & S4 & 7.1 & 22.5 & 1.8 & 7.2 & 51 & 17 \\
\hline & S5 & 6 & 20.3 & 1.4 & 8.8 & 34 & 9 \\
\hline & S6 & 5.8 & 21 & 1 & 8.0 & 36 & 9 \\
\hline & S7 & 3.3 & 16.2 & 3 & 7.7 & 20 & 6 \\
\hline \multirow[t]{6}{*}{ Argillite } & $\overline{\mathrm{A} 1}$ & 5.6 & 23.6 & 1 & 6.2 & 39 & 7 \\
\hline & A2 & 5.5 & 22.8 & 2.9 & 7.9 & 102 & 24 \\
\hline & A3 & 5.9 & 22.7 & 4.5 & 6.6 & 33 & 13 \\
\hline & A4 & 8.1 & 32.8 & 4.9 & 6.6 & 99 & 28 \\
\hline & A5 & 5.8 & 22 & 2.9 & 9.0 & 77 & 13 \\
\hline & A6 & 9.2 & 30.4 & 3.8 & 8.6 & 54 & 15 \\
\hline \multirow[t]{5}{*}{ Colluvium } & $\mathrm{C} 1$ & 6.5 & 22.2 & 0.4 & 5.4 & 30 & 7 \\
\hline & $\mathrm{C} 2$ & 8.4 & 26.4 & 1.6 & 7.2 & 41 & 11 \\
\hline & $\mathrm{C} 3$ & 10 & 24.1 & 0.6 & 5.9 & 42 & 17 \\
\hline & $\mathrm{C} 4$ & 8.2 & 25.8 & 2.2 & 5.1 & 28 & 7 \\
\hline & $\mathrm{C} 5$ & 8.5 & 26.2 & 3.2 & 9.6 & 51 & 9 \\
\hline \multirow[t]{3}{*}{ Soil } & $\mathrm{O} 1$ & 6.6 & 26.3 & 0.5 & 10.5 & 52 & 18 \\
\hline & $\mathrm{O} 2$ & 5.2 & 21.5 & 1.9 & 11.4 & 59 & 19 \\
\hline & $\mathrm{O} 3$ & 6 & 28.7 & 0.8 & 11.2 & 50 & 16 \\
\hline Wadi & W1 & 5.9 & 36.6 & 0.7 & 12.8 & 38 & 18 \\
\hline \multirow[t]{2}{*}{ sediments } & W2 & 6.2 & 31.9 & 1.1 & 9.1 & 38 & 14 \\
\hline & W3 & 7.2 & 35.5 & 0.6 & 13.2 & 25 & 10 \\
\hline
\end{tabular}




\begin{tabular}{llllllll}
\hline Washing & L1 & 5.2 & 27.4 & 3.3 & 6.2 & 65 & 20 \\
sludges & L2 & 5.7 & 25.7 & 3 & 5.9 & 63 & 21 \\
\hline
\end{tabular}

164

165 The high mechanical strength values of the studied samples evidence the method

166 efficiency (Figure 3). Mechanical strength of fired bricks is influenced by temperature,

167 grain size, process of elaboration, and the origin of raw materials. For instance, the

168 finest raw materials such as argillite (samples A2 and A4) exhibit the highest values of

169 mechanical strength (99-102 MPa) and the highest values for flexural strengths (24-28

$170 \mathrm{MPa}$ ) unlike the schist-based or Wadi sediments-based raw materials (Figure3).

171 However, the elaborated bricks from Wadi sediment by this simple approach gives

172 very promising results (compressive strength of $100 \%$ sediments-based bricks fired at

$1731050^{\circ} \mathrm{C}$ ranged from 25 to $38 \mathrm{MPa}$ ) compared with sediments based bricks studied by

174 Mezencevova et al. [7] formed by using the stiff mud extrusion process (compressive

175 strength of $100 \%$ sediments based bricks fired at $1000^{\circ} \mathrm{C}$ ranged from 8 to $12 \mathrm{MPa}$ ). 
176

177

178

179

180

181

182

183

184

185

186

187

188

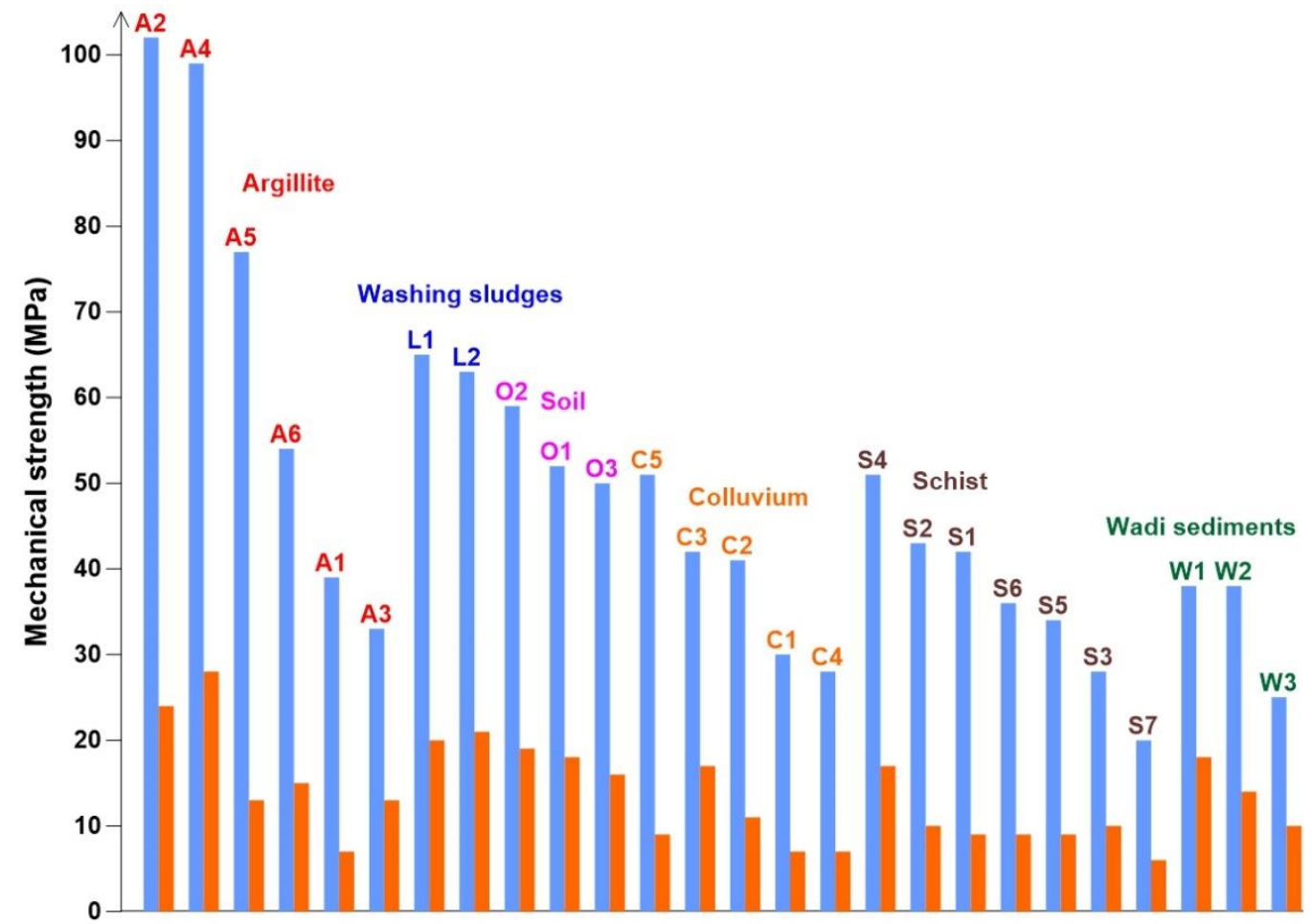

Figure 3: Diagram showing the evolution of the compressive strength (blue bars) and the flexural strength (orange bars) depending on the type of raw materials (fine to coarse).

\section{Conclusion}

This study describes a simple and affordable method of bricks elaboration for any laboratory. The described method allows to calculate very important parameters such as drying and firing shrinkage, drying and firing weight loss, and mechanical strengths, all essential for brick quality control. The obtained results of mechanical strengths are even better than those obtained in literature for fired bricks.

\section{Acknowledgements}

The authors would like to thank the ArGEnCo Laboratory (University of liege) for its support in carrying out the mechanical resistance tests.

\section{References}


189 [1] A. Nkalih Mefire et al., "Mineralogy and geochemical features of Foumban clay 190 191 deposits (west Cameroon): genesis and potential applications," Clay Miner., vol. 53, no. 3, pp. 431-445, Sep. 2018.

[2] T. Monatshebe, A. F. Mulaba-Bafubiandi, and D. Kasongo Nyembwe, 193 "Mechanical properties and mineralogy of artisanal clay bricks manufactured in 194 195 Dididi, Limpopo, South Africa," Constr. Build. Mater., vol. 225, pp. 972-982, Nov. 2019.

196

[3] L. Diko-Makia and R. Ligege, “Composition and Technological Properties of Clays 197 for Structural Ceramics in Limpopo (South Africa)," Minerals, vol. 10, no. 8, p. 700, Aug. 2020.

199

[4] H. E. B. El Idrissi, L. Daoudi, M. El Ouahabi, A. Balo Madi, F. Collin, and N. Fagel, 200 201 "Suitability of soils and river deposits from Marrakech for the manufacturing of earthenware," Appl. Clay Sci., vol. 129, pp. 108-115, 2016.

202

[5] H. E. B. El Idrissi, L. Daoudi, M. El Ouahabi, F. Collin, and N. Fagel, "The influence 203 of clay composition and lithology on the industrial potential of earthenware," Constr. Build. Mater., vol. 172, pp. 650-659, 2018.

[6] A. L. Murmu and A. Patel, "Towards sustainable bricks production: An overview," Constr. Build. Mater., vol. 165, pp. 112-125, 2018.

[7] A. Mezencevova, N. N. Yeboah, S. E. Burns, L. F. Kahn, and K. E. Kurtis, "Utilization of Savannah Harbor river sediment as the primary raw material in production of fired brick," J. Environ. Manage., vol. 113, pp. 128-136, Dec. 2012. 
210 [8] N. El Yakoubi, "Potentialités d'utilisation des argiles marocaines dans l'industrie 211 céramique: cas des gisements de Jbel Kharrou et de Benhmed (Meseta 212 marocaine occidentale). Thèse de Doctorat," p. 212, 2006.

213 [9] M. Hajjaji, S. Kacim, and M. Boulmane, "Mineralogy and firing characteristics of 214 a clay from the valley of Ourika (Morocco)," Appl. Clay Sci., vol. 21, pp. 203-212, 215 2002.

216

[10] D. Wetshondo Osomba, "Caractérisation et valorisation des matériaux argileux de la Province de Kinshasa (RD Congo)," p. 340, 2012.

218 [11] H. E. B. El Idrissi, "Characterization of clays used in the earthenware sector of Marrakech region to improve the quality of the products. UCA in partenership with ULiege. http://hdl.handle.net/2268/212621," 2017.

[12] E. N. 12390-5 European Standard, "Testing hardened concrete - Part 5: Flexural 222 strength of test specimens," p. 9, 2000.

[13] N. F. E. N. 12390-3 European Standard, "Essai pour béton durci - Partie 3 : 224 Résistance à la compression des éprouvettes," p. 15, 2003. 